\title{
New and small e-commerce ventures: The importance of legitimacy and trust
}

Murphy, Gregory B;Smart, Dennis

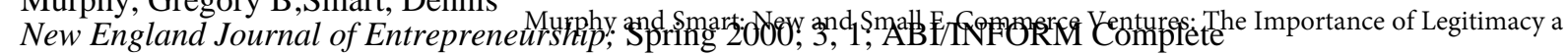
pg. 33

\section{New and Small E-Commerce Ventures: The Importance of Legitimacy and Trust}

\author{
Gregory B. Murphy \\ Dennis Smart
}

Consumers' perceptions of legitimacy and trustworthiness are very important to e-commerce ventures (Cirton, 1998; Hoffman and Novak, 1998; Hunt and Aldrich, 1998). This article briefly reviews the literatures on legitimacy, trust, and e-commerce and integrates them to propose a model of strategies designed to enhance the perceived legitimacy and trustworthiness of independent, new, and/or small ecommerce ventures. The model is extended to suggest strategies for promoting specific consumer behaviors. The article also provides suggestions for future research, including recommendations for testing the proposed model.

A ccording to Access Media International, approximately 600,000 small businesses were engaged in electronic commerce (e-commerce) activities in 1998. That number was expected to more than double to approximately 1.3 million small businesses doing e-commerce by 2000 . The boom in e-commerce customers is equally impressive. Approximately half of all U.S. households have a personal computer with about 50 percent of those actively using the web. According to Jupiter Communications, Internet shoppers are more affluent and better educated than the average American consumer. Total Internet shopping revenues were expected to grow from approximately $\$ 1$ billion in 1997 to roughly $\$ 14$ billion by 2000 (Hoffman and Novak, 1998). Businesses will be doing more to reach potential customers over the web as well. According to the Forrester report, on-line advertising is expected to triple from 1999 to 2003.

The explosive growth in new and small ventures doing e-commerce makes sense given the Internet's reputation as the great equalizer. Although big businesses can and do spend big dollars promoting and maintaining their e-com. merce sites, savvy entrepreneurs can set up and maintain e-commerce sites at a small fraction of the total cost paid by their larger counterparts.

The prospects for new and small e-commerce ventures are promising, but they also face significant challenges. Large, complex e-commerce sites are difficult and expensive to establish and maintain (Wilder, 1998). Getting potential customers to a site is a big challenge and mass advertising, even on the web, can be quite expensive (Wilder, 1998). Finally, even if a new or small venture is able to establish and maintain an effective e-commerce site, and even if the entrepreneur is able to draw potential customers to the site, a daunting challenge remains. Why should an e-commerce shopper purchase a product or service from a relative unknown when well-known competitors with proven track records are also promoting their e-commerce sites (Wilder, 1998)? Unfortunately, the "liability of newness" hypothesis which predicts higher organizational mortality rates for newer businesses (Stinchcombe, 1965) also applies to e-commerce ventures.

Often, new and small ventures lack legitimacy that mitigates the liability of newness. In this context, organizational legitimacy, defined broadly as the acceptance of the organization by its environment, may be viewed as a necessary but insufficient condition for the creation of potential (organization-specific) competitive advantages. For example, as suggested by Barney (1991) and others (Conner, 1991; Grant, 1991; and Hall, 1992), intangible firm resources (including company image and reputation) in conjunction with the firm's product or service offerings, are perhaps the most valuable resource in terms of competitive advantage. And, as Hall (1992) argues, intangible resources (e.g., organizational legitimacy) often act as the "feedstock" of capability differentials that may lead to the acquisition of other resources (e.g., image and reputation) and, ultimately, to a competitive advantage (Smart and Wolfe, 2000). Thus, image and reputation are valued because they contribute to brand equity and the viability of the firm's offerings. Equally important, image and reputation are enduring and not copied easily.

Although disentangling the linkages and relationships among legitimacy, reputation, image, and brand equity are beyond the scope of this research, it is apparent that a new firm must achieve a minimum level of legitimacy before it can hope to develop a competitive advantage generating image or reputation. This problem is particularly keen for e-commerce ventures. Even though traditional new ventures suffer from a lack of sorely needed legitimacy (Zimmerman, 1999), they have a significant advantage in attaining legitimacy over e-commerce ventures. For example, they have physical locations, products, and people that can be seen and verified in person. In contrast, Quint (1999) noted that even experienced e-commerce consumers are careful in deciding what products they are willing to buy sight-unseen.

Accordingly, while attaining legitimacy is important for traditional ventures, it is likely far more important for e-commerce businesses. Hunt and Aldrich (1998), addressing the 
issue of emerging organizational communities, noted that new populations and novel organizational forms have increasingly greater legitimacy problems

Thus, the purpose of this article is twofold. First, the authors examine existing legitimacy and trust issues related to small business activity. They emphasize topics that may be particularly relevant within the scope of e-commerce. The practitioner literature indicates that legitimacy and trust are critical issues for e-commerce ventures (Citron, 1998; and Hoffman and Novak, 1998). Second, the authors develop a model that can be employed by small business owners as they strive to develop the perceived legitimacy and trustworthiness of their firms.

\section{E-Commerce}

As the term e-commerce becomes more ubiquitous, adequate definitions become even more problematic. Although many definitions refer to specific transactions (i.e., buying and selling goods or services electronically), Mougayar (1998) disaggregates the specific buying and selling process into three distinct activities:

1. activities occurring before the actual transaction,

2. the transaction itself, and

3. activities occurring after the transaction.

This broad-based definition suggests that e-commerce opportunities exist for many small business and "conventional" entrepreneurial activities.

For large organizations with complex operations and interrelationships, creating a "complete" e-commerce network (i.e., the integration and automation of internal business processes as well as business-to-business and business-to-consumer processes) can be both costly and time consuming. At the other end of the scale, however, entrepreneurs who want to take advantage of the expanded market opportunities offered by the Internet can establish and maintain "limited" e-commerce sites relatively inexpensively and quickly given the relative simplicity of their operations. These "limited" e-commerce sites that focus on generating on- or off-line sales are the focus of this article.

\section{New and Small E-Commerce Ventures}

New e-commerce ventures that are either an extension or subsidiary of a well-known and respected company inherit considerable legitimacy. The eCommerce Trust Study, for example, found that well-known and respected brick-andmortar establishments were also more likely to have their $\mathrm{e}$ commerce web sites favorably evaluated (Cheskin Research and Studio Archetype/Sapient, 1999). The focus of this study, however, is on independent new and small e-commerce ventures. Lacking the support of and identification with a wellknown and respected parent company, independent new and small e-commerce ventures face a much stronger challenge in building perceived legitimacy and trustworthiness.
Studying independent ventures makes sense in this case since (1) the majority of new and small e-commerce ventures are independent, and (2) studying independent ventures removes the strong biasing effects of prior perceptions (both positive and negative) of the parent organization.

No attempt is made in this article to distinguish between "entrepreneurial" and "nonentrepreneurial" ventures beyond the previously mentioned restrictions of young age and/or small size and independence. The issue of establishing legitimacy and trust is important to all such ventures. However, it is likely that high-growth and innovation-oriented ventures will be particularly influenced by their ability to establish perceived legitimacy and trustworthiness. Râpid growth requires rapid acceptance and innovative organizations often need to convince important stakeholders that their unconventional methods, products, and/or services are worth supporting. In each case, considerable pressure is placed on the organization to establish perceived legitimacy and trust.

\section{Legitimacy}

Organizational legitimacy has been defined as the acceptance of the organization by its environment and has been posited and found to impact both the survival and success of the organization (Kostova and Zaheer, 1999; Ruef and Scott, 1998; and Singh, Tucker, and House, 1986). There are two major orientations commonly applied in addressing the issue of attaining legitimacy (Suchman, 1995).

A more fatalistic or deterministic approach is offered by institutional theorists (Zimmerman, 1999) who argue that legitimacy is attained as a result of isomorphism or conformity to accepted business practices (Deeephouse, 1996; 1999). In effect, this view holds that organizations gain legitimacy by making themselves look like everybody else (DiMaggio and Powell, 1983) and by conforming to a broader set of societal expectations (Parsons, 1960; Pfeffer and Salancik, 1978; Tsang, 1996).

The second orientation'toward attaining organizational legitimacy is more consistent with the concept of strategic choice (Child, 1972) and argues that firms can "instrumentally manipulate and deploy evocative symbols" (Suchman, 1995, p.572) to garner legitimacy. Elsbach (1994), for example, found that representatives for the California cattle industry were able to successfully manipulate the industry's perceived legitimacy by carefully controlling their communications to outsiders. This latter, more voluntaristic perspective is particularly useful to new and small ventures as it suggests firms may influence their perceived legitimacy through the use of legitimizing tactics. The institutional perspective suggests that the only legitimization tactics available are imitation and conformity.

Singh, Tucker, and House (1986) found that external legitimacy had a greater effect on the liability of newness than internal coordination processes. In their longitudinal study of Canadian voluntary social service organizations, 
these researchers found that organizations that attained and maintained community recognized indices of legitimacy, such as being listed in a directory of approved providers, significantly reduced their likelihood of organizational mortality. In their sample, the authors found that attaining external legitimacy was more of a determinant in reducing the rate of organizational mortality than firm age itself, strongly suggesting that organizational legitimacy is a powerful determinant of firm survival. Interestingly, Singh, Tucker, and House (1986) also found that social service organizations that attained and lost important indices of external legitimacy suffered a higher organizational mortality rate after the loss than comparable organizations that never attained the same indices of legitimacy, again pointing to the powerful influence of perceived organizational legitimacy.

Other authors have also examined the effects of organizational legitimacy. Barringer and Greening (1998) argued that organizational legitimacy is essential to achieving successful small business growth through geographic expansion. Shane and Foo (1999) studied 1,292 new franchises started in the United States between 1979 and 1996 and found that considering legitimacy added significantly to traditional economic explanations of survival. Zimmerman and Deeds (1997) studied 103 pharmaceutical biotechnology companies that engaged in initial public offerings (IPO) between 1982 and 1995. They discovered indices of legitimacy to be positively related to firm value for the newly traded companies. Indices of legitimacy included, among others, being mentioned by the popular press and the academic credentials of the management team. Zimmerman (1999) studied the influence of legitimacy on new venture growth in software firms and found that endorsements in the popular business press (e.g., Wall Street Journal) were positively related to sales growth. More specifically, the number of business relationships with Fortune 500 firms, was found to be positively correlated to increases in market growth. Firm age and size were both controlled in the study. The available literature on the subject shows a consistent, positive relationship between organizational legitimacy and venture success.

\section{Trust}

The concept of trust is closely related to that of legitimacy. Aldrich and Fiol (1994) noted that trust is a necessary background condition for the establishment of legitimacy. Clearly, an organization cannot attain legitimacy if it does not also attain the trust of important constituencies. Aldrich and Fiol (1994) further cited Bateson (1998) and Gartner and Low (1990) in noting that "trust, reliability, and reputation are methods of attaining cooperation based on increasing familiarity and evidence" and that "the social process of gaining legitimacy is shaped by the interpersonal processes of achieving trust ...." The need for trust increases as individuals have less information and experience in dealing with each other (Aldrich and Fiol, 1994). Trust is particularly important for new and small ventures since external constituencies typically have very little information and/or very little firsthand experience with the firm (Aldrich and Fiol, 1994).

Rousseau, et al. (1998) defined trust as a "state comprising the intention to accept vulnerability based upon positive expectations of the intentions or behavior of another" (p. 395). Trust, in this definition, is closely related to risk taking, or the behavioral manifestation of trust. The two conditions necessary for trust to exist are risk and interdependence (Rousseau et al., 1998). At this point, a distinction can be made between risk and risk taking. Risk is defined by the context of the situation while one's behavior or reaction in a situation of risk defines risk taking. A situation of risk implies that the decision-maker perceives some degree of outcome uncertainty (Chiles and McMackin, 1996). This uncertainty is a result of the other party's unknown intention and willingness to act appropriately (Chiles and McMackin, 1996). The relationships between risk, trust, and risk taking are that "risk creates an opportunity for trust, which leads to risk taking" (Rousseau et al., 1998 , p. 395). Interdependence exists when "the interests of one party cannot be achieved without reliance on another" (Rousseau et al., 1998, p. 395). The stronger the interdependence and the greater the consequences of opportunistic behavior, the more important trust becomes.

in summary, trust becomes relevant when two or more parties engage in an exchange relationship without full knowledge of the other party's intentions or likely future behavior. Also significant in Rousseau et al.'s definition of trust is the phrase "based upon positive expectations." This implies that trust has a calculative component wherein individuals will trust others only if they believe the other party will not behave opportunistically (Dasgupta, 1988).

Researchers in different disciplines have studied trust. In the organizational behavior and human resource management fields, the bonds of trust between employees and leaders as well as the bonds between employees and their employing organizations have been examined (Whitener et al., 1998). In the strategic management literature, researchers have used the concept of trust to examine the structure and persistence of relationships between partners in cooperative alliances (Gulati, 1995). Specifically, trust is argued and found to reduce the need for formal contracting in strategic alliances (Nooteboom, Berger, and Noordhaven, 1997). In the marketing literature, trust is assumed to be an important operative in allowing the benefits of relationship marketing to emerge (Garbarino and Johnson, 1999). Each of these lines of inquiry, however, focus on trust as a product of previous experience and largely ignore the issue of developing trust. 


\section{Trust Development}

Research on the development of trust has consistently shown that different forms of trust are evidenced at different stages of relationship development and that economic exchange of increasing intensity, duration, and risk requires greater trust. In the marketing literature, for example, the continuum between transactional and relational trust is widely accepted (Garbarino and Johnson, 1999). Transactional trust is that level deemed to be sufficient to allow a low-risk, low-intensity economic exchange to occur such as making a one-time purchase of a fairly well-known product or service. Transactional trust is largely based on assessing the costs and/or rewards of another party's honoring or not honoring the terms of an agreement (Dasgupta, 1988; Doney and Cannon, 1997). Also central to transactional trust is a belief in the other party's ability to complete its part of the agreement.

Relational trust, on the other hand, is that level of trust necessary to allow continuing, relatively high-intensity and high-risk economic exchanges to exist. Relational trust is strongly rooted in personal relationships. Larson's (1992) account of the development of trust between high-growth entrepreneurial firms and their business partners is a good example of relational trust. In each case, the relationships evolved from an initial trial period that more closely resembled transactional trust and incrementally developed into very thick, relational trust that far surpassed the importance of formal contracts. Partners stressed the importance of open information sharing, honesty, fairness, and reciprocity in building and maintaining the strong social context for complex economic exchange to occur.

The concepts of trust may be deeply embedded in personal relationships. As Doney and Cannon (1997) found in a study of purchasing managers, trust did not explain any additional variance in purchasing choice after controlling for previous experience with the supplier and supplier performance. However, as Harrison, Dibben, and Mason (1997) conclude in their account of the cognitive processes of business angels' investment decisions, there appears to be a focus on basic trust in the absence of experience and/or a personal relationship. In fact, it might be argued that trust is most needed and valuable in the absence of experience. Since new and small e-commerce ventures are unlikely to have the benefit of well-developed relationships with their customers, developing trust in the absence of experience becomes very important.

Researchers have been surprised by the high levels of early trust demonstrated by their subjects upon their first meeting or interaction (McKnight, Cummings, and Chervany, 1998). McKnight, Cummings, and Chervany's (1998) model of initial trust formation holds that such trust will be "based on an individual's disposition to trust or on institutional cues that enable one person to trust another without firsthand knowledge" (p. 474). Although e-commerce entrepreneurs have no influence over an individual's disposition to trust, it is possible to manipulate cues made available to the other party and engender trust as a result. The authors incorporate into their model the effects of institution-based trust (structural assurance belief and situational normality belief) or the "security one feels about a situation because of guarantees, safety nets, or other structures" (p. 475) and the effects of cognition-based trust (categorization processes and illusions of control processes), the position that "trust relies on rapid, cognitive cues or first impressions, as opposed to personal interactions" (p. 475).

\section{Trust in E-Commerce}

In the practitioner literature, Cheskin Research and Studio Archetype/Sapient (1999) conducted a notable study on ecommerce trust. The examination concluded that trust develops over time and that growing levels of trust are needed for increasingly significant inquiry and economic exchange to occur. According to the report, e-commerce ventures must first overcome an "untrust" phase before they can focus on subsequently building, confirming, and maintaining trust. Punctuating these stages are the trial, purchase, and habit threshold. The intuitive model holds that ventures must overcome the untrust phase to get the consumer to consider the site (trial threshold). To get the consumer to make a purchase, the venture must have built trust sufficient to satisfy the extrinsic level of trust. To get the consumer to make using the site a habit, the venture must have satisfactorily confirmed the consumer's earlier trust. To continue the habitual relationship, the venture must then focus on maintaining trust.

The study identified six factors or components that communicate trustworthiness: seals of approval, brand, navigation, fulfillment, presentation, and technology.

- Seals of approval included symbols and accompanying text for security (TRUSTe, VeriSign), commerce enabling (MS Commerce Server, ICAT, etc.), and merchant service systems such as MasterCard and Visa.

- Brand consisted of variables such as consumers' awareness of the firm apart from the web, how consistent the site is with consumers' perceptions of the firm, benefit clarity, mentioned affiliations with wellknown Internet portals and aggregators (e.g., Yahoo!, Excite, etc.), relationship marketing (sending updates and notices to customers), facilitating interactions between shoppers, and the depth and breadth of product offerings on the site.

- Navigation involved navigation clarity, access, and reinforcement (navigational prompts, guides, instructions, etc.). 
- Fulfillment included the protection of personal information, the provision of a tracking system, identifying available recourse(s) in the event of problems, clarifying return policies, and keeping the process simple. . .

- Presentation consisted of communicating a clear purpose for the site, artistry in developing the site, and how much the site resembles other sites the consumers have come to trust.

- Technology referred to the overall functionality and speed of the site.

Although the study provides considerable and valuable information to e-commerce managers as to what factors are associated with the perception of trustworthiness, it does not adequately address the needs of new and small e-commerce ventures. By including the Internet sites of large, well-established and known firms in the study, the results are biased in favor of those firms that consumers are likely to have had prior experience with or knowledge of. For example, the study listed the 12 most trusted sites as Yahoo!, Wal-Mart, Netscape, Infoseek, Blockbuster Video, Excite, Borders, Amazon.com, USA Today, Dell, Internet Explorer, and Lycos. The 10 least trusted sites were Monster Board, Spinner, Cyberkids, The Well, JenniCam, Carpoint, @Home, Drugstore.com, Cyberian Outpost, and The Palace. Although the authors note that the ratings are not strictly a function of familiarity, the two do appear to be strongly correlated.

The finding that some well known businesses might score lower than unknown businesses is consistent with the finding of Singh et al. (1986), that organizations which had lost symbols of legitimacy, had a higher mortality rate than organizations that never attained such symbols. Prior dissatisfaction with a well-known company may have resulted in low ratings. In any case, the issue of prior familiarity is problematic in the study and creates the possibility that the results are less a function of perceptions of the web site than previously conceived perceptions of the firms. This dilemma also limits the usefulness of the study to new and small e-commerce ventures that probably do not enjoy such popularity. Additionally, new and small e-commerce ventures should be more concerned with developing legitimacy with their target markets by building transactional or calculative trust. Well-established firms, on the other hand, are likely to be operating at the level of relational trust and are thus likely to be more highly rated in the study. As a result, the study may have more closely captured consumers' higher-order emotional responses than their basic willingness to participate in an economic exchange.

\section{Legitimacy and Trust in New and Small E- Commerce Ventures}

There is evidence that many consumers have little trust for e-commerce ventures in general (Citron, 1998; and
Hoffman and Novak, 1998). These studies should be tempered by the fact that Internet-based business activity, both at the business-to-business and business-to-consumer levels, is still in its infancy. The importance of trust in facilitating the development of e-commerce, however, is widely recognized in both the academic and practitioner literatures (Hibbard, 1999; Hunt and Aldrich, 1998). Singh et al.'s (1986) research, showing that organizational legitimacy mediates the relationship between newness and organizational mortality, suggests that the issue of building and maintaining trust is even more important for new and small e-commerce ventures than for larger, more established ventures. Accordingly, attention is now turned to developing a model of legitimacy and trust for new and small ecommerce ventures.

Exhibit 1 presents a general model in which a firm's perceived organizational legitimacy and trustworthiness are a function of the exchange relationships they maintain with important stakeholders. To build and sustain perceived legitimacy and trustworthiness, organizations need the support of important stakeholders (Aldrich and Fiol, 1994). Regulatory agencies, for example, support the perceived legitimacy and trustworthiness of a firm by licensing the organization, thereby indicating compliance with expected standards of behavior. In exchange for their support, stakeholders anticipate receiving valued benefits from the organization: employees expect to be paid, financiers anticipate positive returns, regulatory agencies expect fair play and compliance, etc. Satisfying the interests of an important stakeholder may increase the likelihood of receiving needed support of another stakeholder. For example, having a patent or needed governmental approval may increase the likelihood of attaining external financing. While recognizing the importance of multiple stakeholders in determining the perceived legitimacy and trustworthiness of the firm, this article focuses on the relationship between thie firm and one important stakeholder group: customers. Specifically, this article addresses the ability of the firm to promote its perceived legitimacy and trustworthiness in the-eyes of its target market. Receiving the support of customers is essential to generating sales.

Exhibit 2 presents a model in which legitimacy and trust, as perceived by the target market, are a function of isomorphism and strategic manipulation. The model is consistent with prior research and holds that perceived legitimacy and trust will be positively associated with the venture's ability to attain needed resources from the environment

Isomorphism should be positively related to perceived organizational legitimacy and transactional trust. This proposition, coming from the organizational theory literature, has been supported by the eCommerce Trust Study (Cheskin Research and Studio Archetype/Sapient, 1999), that found resemblance to a trusted site to be positively associated with perceived trustworthiness. By imitating the 


\section{Exhibit 1}

\section{Multiple Stakeholders and Perceived Organizational Legitimacy and Trustworthiness}

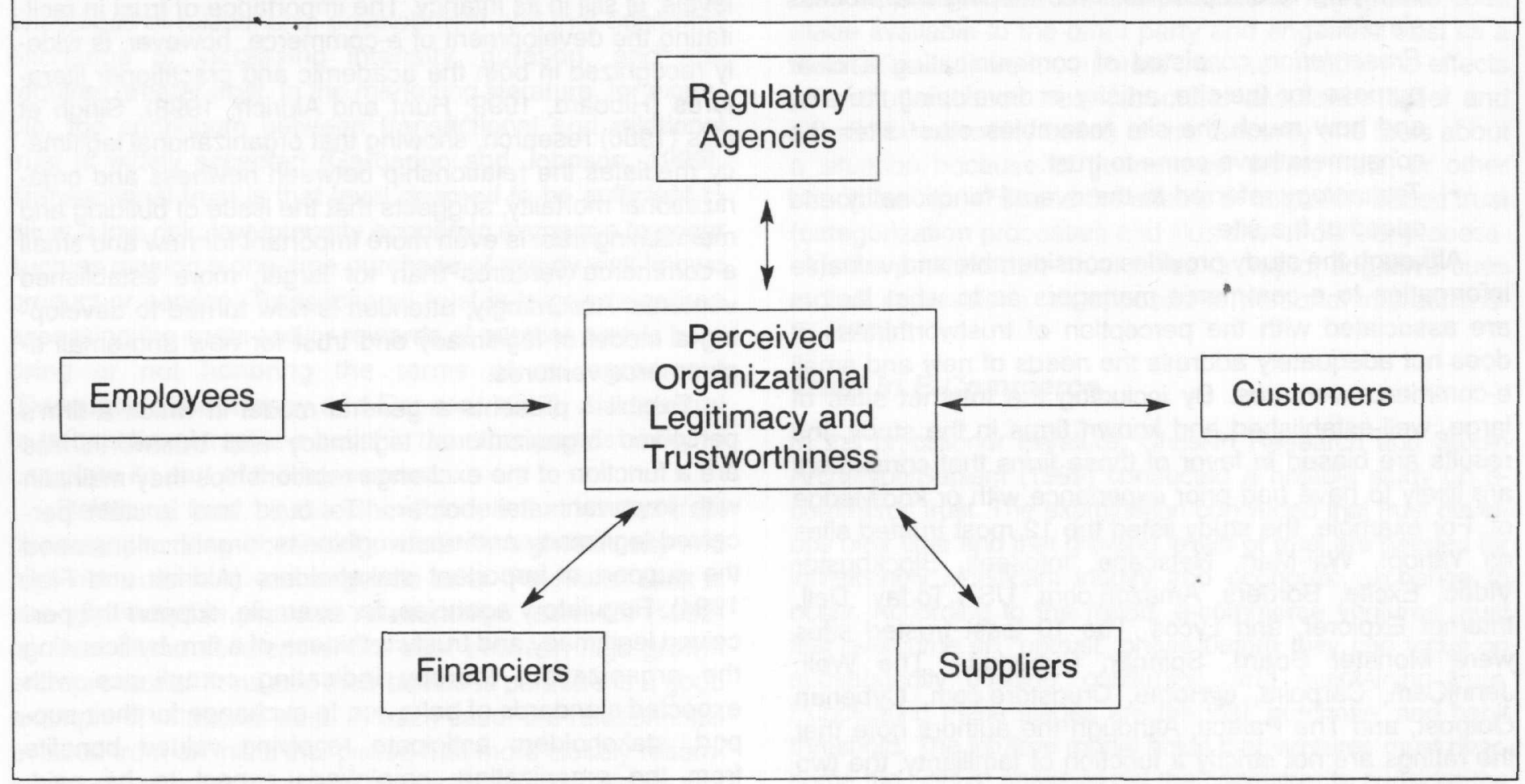

design and features of well known web sites, new and small ventures have the advantage of what McKnight, Cummings, and Chervany (1998) referred to as situational normality beliefs. Situational normality beliefs are also likely to be reinforced by consumer perceptions that the venture is in compliance with legal and regulatory requirements as well as general expectations of acceptable business practices. This perspective is also consistent with what Aldrich and Fiol (1994) identified as sociopolitical legitimacy -"the extent to which a new form conforms to recognized principles or accepted rules and standards" (pp. 645-646). Fewer questions and challenges as to the form of the e-commerce enterprise should result in more favorable initial trusting beliefs (McKnight, Cummings, and Chervany, 1998) and produce higher levels of transactional trust. The lack of any personal interaction or experience, however, implies that isomorphism in itself will not be sufficient to engender relational trust unless the e-commerce venture successfully imitates features expressly designed to do so.

Effective strategic manipulation of communicated information should be positively related to perceived organizational legitimacy and trust. The proposition that new and small e-commerce ventures can strategically manipulate cues is of critical importance to practitioners. Without this proposition, all that new and small ventures can do is imitate and conform-a position that may reduce the likelihood of organizational mortality, but will unlikely lead to any long-term advantage (Porter, 1996). New and small ecommerce ventures can instrumentally manipulate consumers' trust by communicating transference, competency, and value and goal congruence. Ventures can also manipulate perceived trust by communicating and providing structural assurances and successful fulfillment. Successfully employed, transference, competency, and structural assurances should significantly increase the consumer's transactional trust. Value and goal congruence and fulfillment, on the other hand, offer potential for building relational trust and may be particularly useful for those new and small e-commerce ventures that require higher levels of trust to conduct business.

Transference is a potentially powerful tool for building transactional trust (Doney and Cannon, 1997). It is gained as a result of using the name of a well-known and hopefully well-respected third party. Although the consumer may not have any experience with a specific e-commerce site, the consumer may form a favorable trust belief of that site if he or she perceives the third party to be highly legitimate and worthy of deep trust. The concept of transference is largely parallel to that of identification (Zimmerman, 1999) and can be gained by communicating product brand identification (Cheskin Research and Studio Archetype/ 


\section{Exhibit 2}

Model of Perceived Organizational Legitimacy and Trust for New and Small E-Commerce Ventures

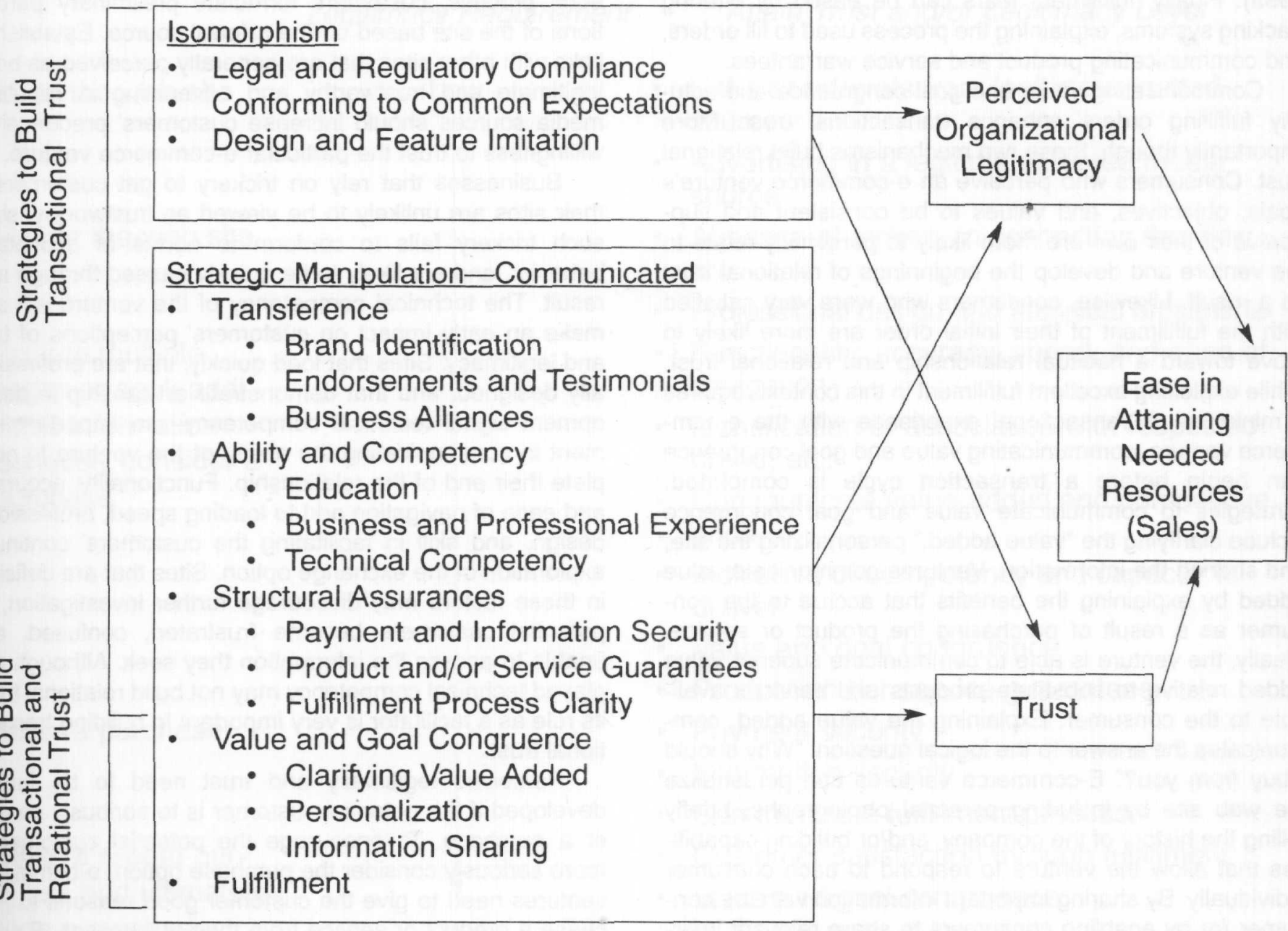

Sapient, 1999), endorsements and testimonials, and important business alliances (Zimmerman, 1999). Seals of approval, as identified by the eCommerce Trust Study (Cheskin Research and Studio Archetype/Sapient, 1999) also serve as a powerful source of transference through their implicit endorsement of the site.

Communicating the ability or competency necessary to complete one's part of an agreement is an important step in developing the consumer's transactional trust in the site. Ability and competency can be communicated by providing cues as to the credentials of the e-commerce venture itself and of the entrepreneurs behind the business. Specific credentials relevant to new and small e-commerce ventures that can be communicated through the use of cues include business experience, professional experience, technical competency, and formal education accomplishments.
Simple statements such as "more than 20 years experience in the field" communicate a strong sense of competency. Technical competency cues, on the other hand, do not need to be directly communicated; they can be inferred from the speed, functionality, and quality of the web site itself (Cheskin Research and Studio Archetype/Sapient, 1999).

Providing structural assurances is a critical step in gaining transactional trust for new and small e-commerce ventures. Justified or not, many shoppers are not comfortable with issues such as payment and information security and the probability of fulfillment given an on-line order (Citron, 1998; Kuchinskas, 1999; Wilson, 1997). E-commerce vendors can partially overcome payment security fears by using symbols of recognized transaction security processes such as VeriSign and by including text that explains the security system to reassure the consumer of the low risk of 
making payments over the web (Cheskin Research and Studio Archetype/Sapient, 1999). Likewise, communicating policies designed to protect sensitive information can help alleviate consumer fears about information security leaks (Cheskin Resedrch and Studio Archetype/Sapient, 1999). Finally, fulfillment fears can be eased by offering tracking systems, explaining the process used to fill orders, and communicating product and service warrantees.

Communicating value and goal congruence and actually fulfilling orders enhance transactional trust. More importantly though, these two mechanisms build relational trust. Consumers who perceive an e-commerce venture's goals, objectives, and values to be consistent and supportive of their own are more likely to personally relate to the venture and develop the beginnings of relational trust as a result. Likewise, consumers who were very satisfied with the fulfillment of their initial order are more likely to move toward a habitual relationship and relational trust. While exploiting excellent fulfillment in this context requires a minimum of transactional experience with the e-commerce venture, communicating value and goal congruence can begin before a transaction cycle is completed. Strategies to communicate value and goal congruence include clarifying the "value added," personalizing the site, and sharing the information. Ventures communicate value added by explaining the benefits that accrue to the consumer as a result of purchasing the product or service. Ideally, the venture is able to communicate superior value added relative to substitute products and services available to the consumer. Explaining the value added, communicates the answer to the logical question: "Why should I buy from you?" E-commerce ventures can personalize the web site by including personal photographs, briefly telling the history of the company, and/or building capabilities that allow the venture to respond to each consumer individually. By sharing important information with the consumer (or by enabling consumers to share relevant information with each other), the electronic merchant increases the patron's relevant knowledge level, decreasing the likelihood that the shopper will be a victim of opportunistic behavior due to information asymmetries. In addition, the entrepreneur is intentionally making himself or herself vulnerable in the eyes of the consumer. Making oneself vulnerable indicates trust in the other party and is likely to be met with corresponding trust.

\section{Encouraging Customer Action}

Having developed a model of perceived legitimacy and trust development for e-commerce ventures, attention is now turned to the issue of manipulating perceived legitimacy and trust to encourage important customer actions. Exhibit 3 shows critical customer actions in the leftmost column. The actions are arrayed temporally and in order of increased intensity. As a result, the corresponding levels of trust and perceived legitimacy must also increase as the intensity level of customer actions increase if the e-commerce venture is going to successfully attract customers.

Gaining trust and legitimacy begins before the consumer ever arrives at the web site. Through the transference process, customers formulate preliminary perceptions of the site based on the referral source. Establishing links with other sites that are generally perceived as being legitimate and trustworthy and advertising in reputable media sources should increase customers' preconceived willingness to trust the particular e-commerce venture.

Businesses that rely on trickery to get customers to their sites are unlikely to be viewed as trustworthy, since such trickery fails to conform to norms of acceptable behavior, and are likely to be quickly passed through as a result. The technical competency of the venture will also make an early impact on customers' perceptions of trust and legitimacy. Sites that load quickly, that are professionally designed, and that demonstrate artisanship in development signal technical competency-an important element in communicating the ability of the venture to complete their end of the relationship. Functionality, accuracy, and ease of navigation add to loading speed, professional design, and skill in facilitating the customers' continued exploration of the exchange option. Sites that are deficient in these factors may discourage further investigation, as potential customers become frustrated, confused, and unable to access the information they seek. Although displayed technical competency may not build relational trust, its role as a facilitator is very important in building transactional trust.

Perceived legitimacy and trust need to be further developed if the potential customer is to seriously consider a purchase. To encourage the potential customer to more seriously consider the purchase option, e-commerce ventures need to give the customer good reasons to purchase a product or service from their businesses. E-commerce ventures can use a variety of different strategies and manipulate the content cues in their favor, thereby enhancing their perceived legitimacy and trust. Transference can, once ağain, become a powerful motivator at this point. Potential customers may be favorably impressed by the brand names carried or by the testimonial of an individual they respect or believe to be authentic. Adding statements that communicate professional, business, or personal competency can be very powerful in instances where the potential customer might logically wonder about the ability of the site to deliver on its promises. For example, a site specializing in antiques would benefit greatly by communicating the knowledge and reputations of the primary operators. Communicating value added and a fair price are also potentially powerful strategies that may be particularly useful at this point. Aldrich and Fiol (1994) noted that internally consistent stories 


\section{Exhibit 3}

Consumer Actions and Strategies to Meet the Required Trust and Perceived Legitimacy

Customer Action Trust and Perceived
Legitimacy Requirement
Key Points Suggested and/or Needed to Attain Trust and/or Legitimacy Level
Go to the web site

Stay at the web site

Explore multiple pages or seek additional information Seriously consider a purchase

Make a purchase

Make a repeat purchase and ultimately form a purchase habit
Low

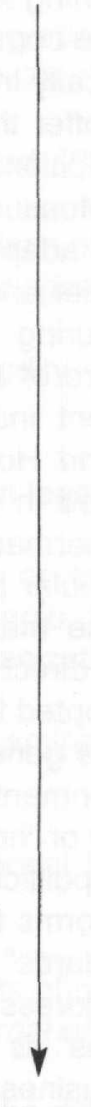

High
- Links or referrals from legitimate/trusted sources

- Advertising in a legitimate/trusted media source

- Absence of trickery in connecting the viewer

- Professional design and technical artisanship

- Functionality, accuracy, speed, and ease of navigation

- Identification or association with respected brand, etc.

- Communicate value added and competitive price

- Indicators of competency and capacity to deliver

- Value and goal congruence

- Product and/or service guarantees

- Payment security

- Information security

- Communicate fulfillment process

- Customer satisfaction through fulfillment

- Value and goal congruence

- History of "fair play" enhance the perceived legitimacy of an organization. Consistent stories that communicate a compelling sense of value creation are particularly powerful in enhancing perceived legitimacy. Such stories can also be used to communicate value and goal congruence, further inspiring perceived legitimacy and trustworthiness.

Next, the venture must overcome the customers' potential fears about payment and information security as well as their concerns about the fulfillment process. As previously mentioned, using recognized payment security services and accompanying text can alleviate fears of payment security violations. Likewise, clearly communicating, stressing, and honoring a policy of information privacy can soften customer fears in this area. Offering product and/or service guarantees, explaining how orders will be filled, and what recourses are available should also ease customer concerns. Communicating an excellent history of reliability and dependability in filling orders on time and to specifications may also help potential customers feel more comfortable in clicking the purchase button.

So far the focus has been on strategies that do not require previous experience, a necessary orientation given the likelihood that most customers will have little or no familiarity with the new or small e-commerce venture. To develop relational trust, however, and encourage the customer to ultimately become a regular customer, some measure of experience is necessary. First, satisfactory fulfillment of the initial transaction that meets all promises and 
expectations created, confirms customers' transactional trust and encourages them to move beyond that extrinsic level. Successful fulfillment also reinforces the customers' perceptions of value and goal congruence, creating even greater meaning for personalization and information-sharing efforts as customers strengthen their emotional ties to the venture. Finally, as Murphy's law dictates, when despite best efforts something ultimately does go wrong, the venture's response to the discrepancy will greatly influence the strength of the customer's relationship with the venture. Ideally, the customer will be clearly convinced that the venture is committed to "fair play" and as a result, clearly worthy of their continued trust.

A final caution: As Singh et al. noted the strong negative effects of gaining and loosing perceived legitimacy, e-commerce ventures should be even more concerned about meeting customer expectations once trust has been created. Jeffrey Bezos, founder of Amazon.com, noted that the communicative power of the Internet allows satisfied and dissatisfied customers to quickly share their pleasure or grief with an extremely large number of customers (Kotha and Dooley, 1998). Accordingly, violating previously established trust may be far more damaging to a new or small e-commerce venture than never gaining trust in the first place.

\section{Suggestions for Future Research}

This study has provided a theoretical model for considering and examining the relationships between customers and perceived organizational legitimacy and trustworthiness for independent new and small e-commerce ventures. Other relationships between the organization and important stakeholders depicted in Exhibit 1 offer room for further theoretical and empirical development. For example, future research may investigate the effects employees have on the perceived legitimacy and trustworthiness of an organization. If the restriction of only considering independent new and small ventures is relaxed, then another interesting aspect of perceived organizational legitimacy and trustworthiness can be considered: the influence of the parent organization on the e-commerce venture. The relative ability of independent and nonindependent ventures to acquire and maintain perceived legitimacy and trustworthiness could then be investigated. Another issue not addressed in this study is considering the effects of country of origin on perceived legitimacy and trustworthiness. The extent that international e-commerce ventures are willing and able to exploit or disguise their country of origin may influence perceptions of legitimacy and trustworthiness.

Returning to the model presented here, web surveys of potential e-commerce customers offer a promising method to empirically investigate the proposed relationships. Web surveys offer the benefit of enhanoing the context of the study. Additionally, they offer the ability to gather data quickly. Measures of trust are readily available and can easily be adapted for web survey use (Feick and Higie, 1992; Keller and Aaker, 1992).

Measuring perceived organizational legitimacy presents more of a challenge. Legitimacy is typically treated as a latent independent variable. For example, Singh, Tucker and House (1986) operationalized legitimacy as being listed in a directory of approved service providers and Zimmerman and Deeds (1997) used being mentioned in the popular business press and the academic credentials of the management team as indices of legitimacy. However, direct measures of perceived legitimacy could be easily adopted for web survey use. Aldrich and Fiol (1994) refined the general definition of legitimacy, acceptance by the environment, by describing what they labeled cognitive legitimacy or "how taken for granted a new form is" (p. 645) and sociopolitical legitimacy or "the extent to which a new form conforms to recognized principles or accepted rules and standards" (p. 646). Although Aldrich and Fiol were directly addressing the issue of industry creation and used "new forms" as a result, the work can easily be extended to new businesses. Following this lead, direct measures might include questions such as:

- "Does this venture appear to be following an accepted business model?"

- "Does this venture appear to conform to recognized principles, rules and standards?"

\section{Endnotes}

Aldrich, H., and Fiol, C. (1994). Fools rush in? The institutional context of industry creation. Academy of Management Review, 19, 645-670.

Barney, J. B. (1991). Firm resources and sustained competitive advantage. Journal of Management, 17, 99-120.

Barringer, B., and Greening, D. (1998). Small business growth through geographic expansion: A comparative case study. Journal of Business Venturing, 13, 467-492. 
Bateson, P. (1988). The biological evolution of cooperation and trust. In D. Gambetta (ed.), Trust: Making and Breaking Cooperative Relations, New York: Blackwell.

Cheskin Research and Studio Archetype/Sapient. (1999). eCommerce Trust Study. Available online from Cheskin Research and Studio Archetype/Sapient: January 12.

Child, J. (1972). Organizational structure, environment and performance: The role of strategic choice. Sociology, 6 , $1-22$.

Chiles, T., and McMackin, J. (1996). Integrating variable risk preference, trust, and transaction cost economics. Academy of Management Review, 21, 73-79.

Citron, A. (1998). The net cannot be trusted. The Industry Standard, May 28.

Conner, K. R. (1991). A historical comparison of resource-based theory and five schools of thought within industrial organization economics. Journal of Management, 17, 121-154.

Dasgupta, P. (1988). Trust as a commodity. In D. Gambetta (ed.), Trust: Making and Breaking Cooperative Relations, New York: Blackwell.

Deephouse, D. (1996). Does isomorphism legitimate? Academy of Management Journal, 39, 1024-1039.

Deephouse, D. (1999). To be different or to be the same? It's a question of strategic balance. Strategic Management Journal, 20, 147-166. DiMaggio, P. and Powell, W. (1983). The iron cage revisited: Institutional isomorphism and collective rationality in organizational fields. American Sociological Review, 48, 147-160.

Doney, $P_{1}$. and Cannon, J. (1997). An examination of the nature of trust in buyer-seller relationships. Journal of Marketing, 61, 35-51.

Elsbach, K. (1994). Managing organizational legitimacy in the California cattle industry. Administrative Science Quarterly, 39, 57-88.

Feick, L., and Higie, R. (1992). The effects of preference heterogeneity and source characteristics on ad processing and judgement about endorsers. Journal of Advertising, 21, 9-24.

Garbarino, E., and Johnson, M. (1999). The different roles of satisfaction, trust, and commitment in customer relationships. Journal of Marketing, 63, 70-87.

Gartner, W., and Low, L. (1990). Trust as an organizing trope. Paper presented at the annual meeting of the Academy of Management, San Francisco.

Grant, R. M. (1991). The resource-based theory of competitive advantage: Implications for strategy formulation. California Management Review, 33, 114-135.

Gulati, R. (1995). Does familiarity breed trust? The implications of repeated ties for contractual choice in alliances. Academy of Management Journal, 38, 85-112.

Hall, R. (1992). The strategic analysis of intangible resources. Strategic Management Journal, 13, 135-144.

Harrison, R., Dibben, M., and Mason, C. (1997). The role of trust in the informal investor's investment decision: An exploratory analysis. Entrepreneurship, Theory and Practice, 21, 63-81.

Hibbard, J. (1999). E-commerce: It's a matter of trust. InformationWeek, 717, 14. 
Hoffman, D., and Novak, T. (1998). Trustbuilders vs. trustbusters. The Industry Standard, May 11.

Hunt, C., and Aldrich, H. (1998). The second ecology: Creation and evolution of organizational communities. In B. Staw and L. Cummings, Research in Organizational Behavior, 20, 267-301.

Keller, K., and Aaker, A. (1992). The effects of sequential introduction on brand extensions. Journal of Marketing Research, 29, 35-50.

Kostova, T., and Zaheer, S. (1999). Organizational legitimacy under conditions of complexity: The case of the multinational enterprise. Academy of Management Review, 24, 64-81.

Kotha, S., and Dooley, E. (1998). Amazon.com. In C.W. Hill and G.R. Jones (eds.), Strategic Management: An Integrated Approach, Boston: Houghton-Mifflin.

Kuchinskas, S. (1999). In web sites we trust? Mediaweek, 9, 38-39.

Larson, A. (1992). Network dyads in entrepreneurial settings: A study of the governance of exchange relationships. Administrative Science Quarterly, 37, 76-104.

McKnight, D., Cummings, L., and Chervany, N. (1998). Initial trust formation in new organizational relationships. Academy of Management Review, 23, 473-490.

Mougayar, W. (1998). Opening Digital Markets, New York: McGraw Hill.

Nooteboom, B., Berger, H., and Noorderhaven, N. (1997). Effects of trust and governance on relational risk. Academy of Management Journal, 40, 308-338.

Parsons, T. (1960). Structure and Process in Modern Societies, Glencoe, IL: Free Press.

Pfeffer, J., and Salancik, G. (1978). The External Control of Organizations, New York: Harper and Row.

Porter, M. (1996). What is strategy? Harvard Business Review, November-December, 61-78.

Quint, B. (1999). E-commerce and traditional online. Information Today, 16, 10-11+.

Rousseau, D., Sitkin, S., Burt, R., and Camerer, C. (1998). Not so different after all: A cross-discipline view of trust. Academy of Management Review, 23, 393-404.

Ruef, M., and Scott, W. (1998). A multidimensional model of organizational legitimacy: Hospital survival in changing institutional environments. Administrative Science Quarterly, 43, 877-904.

Shane S., and Foo, M. (1999). New firm survival: Institutional explanations for nèw franchiser mortality. Management Science, 45, 142-159.

Singh, J., Tucker, D., and House, R. (1986). Organizational legitimacy and the liability of newness. Administrative Science Quarterly, 31, 171-193.

Smart, D. L., and Wolfe, R.A. (2000). Examining sustainable competitive advantage in intercollegiate athletics: A resource-based view. Journal of Sport Management, 14, 133-153.

Stinchcombe, A. (1965). Social structure and organizations. In E. G. Marsh (ed.), Handbook of Organizations. Chicago: Rand McNally.

Suchman, M. (1995). Managing legitimacy: Strategic and institutional approaches. Academy of Management Review, 20, 571-601. 
Tsang, W. (1996). In search of legitimacy: The private entrepreneur in China. Entrepreneurship, Theory and Practice, 21, 21-30.

Whitener, E., Brodt, S., Korsgaard, M., and Werner, J. (1998). Managers as initiators of trust: An exchange relationship framework for understanding managerial trustworthy behavior. Academy of Management Review, 23, 513-530.

Wilder, C. (1998). E-commerce myths and realities. InformationWeek, 712, 52-63.

Wilson, T. (1997). Trust trails E-commerce technology," Internetweek, 655, 1,59.

Zimmerman, M. (1999). New venture legitimacy: The influence of legitimacy upon the growth of new ventures. Paper presented at the Academy of Management Annual Meeting, Chicago.

Zimmerman, M., and Deeds, D. (1997). Legitimacy and the initial public offerings of biotechnology firms. Frontiers of Entrepreneurship Research.

\section{MESE}

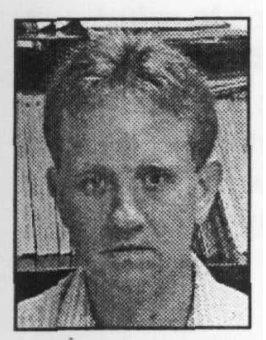

Gregory B. Murphy is an assistant professor of management at the University of Nebraska-Omaha. He received his Ph.D. in business administration from the University of Houston. His research interests are in the areas of entrepreneurship and electronic commerce.

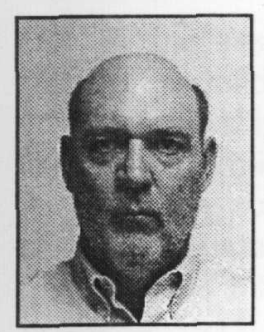

Dennis L. Smart is an associate professor of management at the University of Nebraska's (Omaha) College of Business Administration. He holds a Ph.D in strategic management from Texas A\&M University. His research interests are in the development of entrepreneurial activities in large organizations, organizational restructuring, corporate governance, and electronic commerce. 